\title{
Preparation, microstructure and properties of biomimetic nanocomposite coating
}

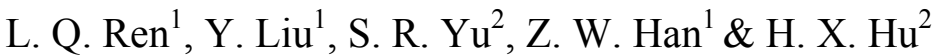 \\ ${ }^{1}$ The Key Laboratory for Terrain-machine Bionics Engineering, \\ The Ministry of Education, Jilin University, People's Republic of China \\ ${ }^{2}$ College of Materials Science and Engineering, Jilin University, \\ People's Republic of China
}

\begin{abstract}
Bamboo is a typical natural composite material, and its special structure and excellent properties provide important information for the biomimetic design of composites. To strengthen the fiber content of bamboo distributed in a gradient, a bimimetic nano- $\mathrm{Al}_{2} \mathrm{O}_{3}$ composite coating was designed and prepared on the surface of metal parts using a nanocomposite electrodeposition method. The optimal technology parameters were obtained, such as current density, $\mathrm{PH}$ value, nano- $\mathrm{Al}_{2} \mathrm{O}_{3}$ content in electrolyte, and style of stirring etc after the experiments. The microstructure of the biomimetic nanocomposite gradient coating was very dense, and the contents of nano- $\mathrm{Al}_{2} \mathrm{O}_{3}$ were distributed in the gradient. The microhardness of the composite coating changed from the surface to the inside in the gradient also. Moreover, the wetting angle between water and composite coating obviously increased and reached $97^{\circ}$ at room temperature.
\end{abstract}

Keywords: nanocompostite coating, biomimetic, preparation, microstructure, properties.

\section{Introduction}

The bamboo is a typical example of a naturally occurring composite material. The structural character, mechanical properties, and wear resistance of bamboo and the biomimetic application of bamboo structures have been widely used in biomimetic material fields in recent years. The special structure and excellent properties of bamboo have yielded important information for the biomimetic 
design of advanced composites, and an important progress in the research field was made.

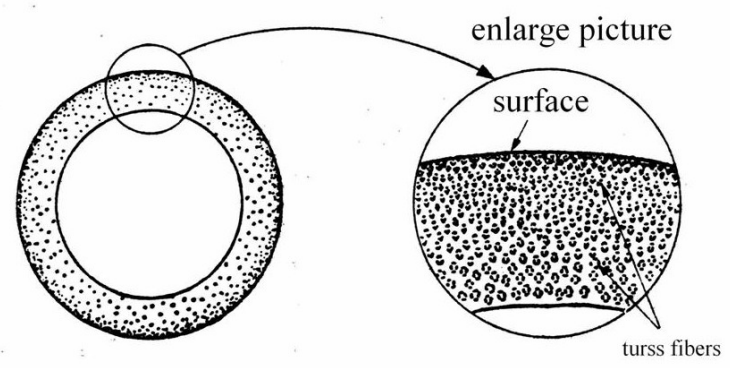

Figure 1: The structure of bamboo's cross-section [1].

The microstructure of bamboo mainly includes thick-walled cells and thinwalled cells. The thick-walled cells provide the strength of bamboo, referred to as truss fibers, and the thin-walled cells constitute the matrix of bamboo [2]. The hardness of truss fibers is higher than the matrix. The wear resistance of bamboo's surface is improved due to the content of truss fibers decreases gradually from the surface to interior. Corresponding to bamboo's microstructure character, the content of nano- $\mathrm{Al}_{2} \mathrm{O}_{3}$ in the biomimetic nanocomposite coating varies from the surface to the interior, and this structure avoids the bad interface bonding and illogical stress distribution induced by the sudden change of the structure and properties.

According to the structural character of nature biomaterials such as bamboo, where the strengthening phase is distributes in the matrix, a kind of new biomimetic gradient nanocomposite coating was designed and prepared by using a bionics viewpoint and a nanocomposite electrodeposition method. The composition in the coating distributes in gradient from the substrate to the surface of the coating. A good bonding between the coating and substrate was obtained. The coating surface is hydrophobic, and its hardness is high.

\section{Preparation of biomimetic $\mathrm{Nano}-\mathrm{Al}_{2} \mathrm{O}_{3} / \mathrm{Ni}-\mathrm{cCo}$ gradient composite coating}

\subsection{Choice of coating materials}

The nanocomposite coating consisted of matrix metal and nano-grains. Ni was chosen as the matrix metal, and a small amount of Co was added. Nano- $\mathrm{Al}_{2} \mathrm{O}_{3}$ particles were chosen as the second phase nanograins. Compared with micrograins, the nanograins have special properties due to dimension character. The surface effect is the dominant factor [3]. The average granularity of nano- $\mathrm{Al}_{2} \mathrm{O}_{3}$ is $60 \mathrm{~nm}$, with a purity greater than $99.99 \%$, specific surface area $180 \pm 10 \mathrm{~m}^{2} / \mathrm{g}$, and physical phase $\gamma-\mathrm{Al}_{2} \mathrm{O}_{3}$. 


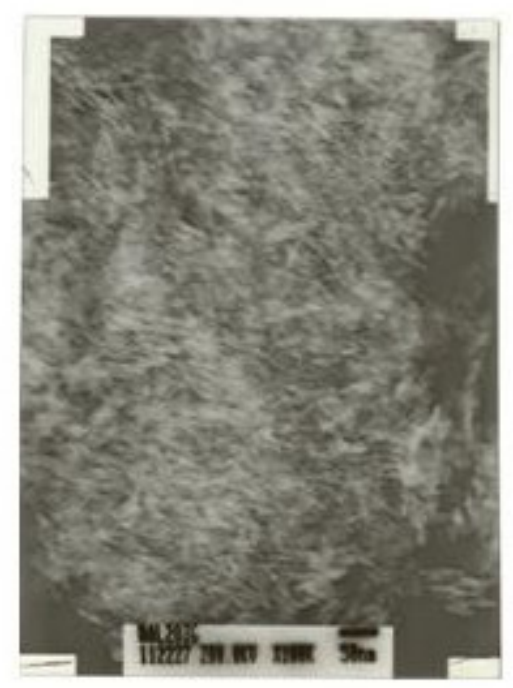

Figure 2: $\quad$ Morphology of nano $\gamma-\mathrm{Al}_{2} \mathrm{O}_{3}$.

Watt electrolyte is widely used in plating $\mathrm{Ni}$ and consists of $\mathrm{NiSO}_{4}, \mathrm{NiCl}_{2}$ and $\mathrm{H}_{3} \mathrm{BO}_{3}$. To prevent pinholes, a small amount of wetting agent, such as $\mathrm{Na}_{2} \mathrm{SO}_{4}$ $12 \mathrm{CH}_{2}$, is usually added. The advantages of the electrolyte are that it is cheap and easy to operate and safeguard. The brittleness and inner stress of the coating were small, and the speed of deposition was quicker.

\subsection{Optimization of the preparing technology parameters of nanocompose coating}

In the course of compose electrodeposition, the optimal technology parameters were necessary to obtain a high quality coating. The optimal technology parameters, such as the current density, stir method, $\mathrm{pH}$ value and temperature of electrolyte, time and the content of nanoparticles etc, largely affected the quality of coating in the electrodeposit experiment after the electrolyte was determined. The optimal technology parameters were obtained by orthogonal testing, and they are the current density of $4 \mathrm{~A} / \mathrm{dm}^{2}, \mathrm{pH}$ value $3 \sim 4$, electrolyte temperature $40^{\circ} \mathrm{C} \sim 50^{\circ} \mathrm{C}$, the content of nano- $\mathrm{Al}_{2} \mathrm{O}_{3}$ in electrolyte $20 \mathrm{~g} / \mathrm{l}$, and the stirring method used was a mechanical stir with ultrasonic vibration.

\subsection{The preparation method of biomimetic $\mathrm{Nano}-\mathrm{Al}_{2} \mathrm{O}_{3} / \mathrm{Ni}-\mathrm{Co}$ gradient composite coating}

The biomimetic nano- $\mathrm{Al}_{2} \mathrm{O}_{3} / \mathrm{Ni}-\mathrm{Co}$ gradient composite coating was prepared on the surface of metal parts. Firstly, Ni-Co alloy without nano- $\mathrm{Al}_{2} \mathrm{O}_{3}$ was plated for 
$30 \mathrm{~min}$. Then nano- $\mathrm{Al}_{2} \mathrm{O}_{3}$ was slowly added to the plating solution in the amount of $10 \mathrm{~g} / \mathrm{l}$ and plated for $50 \mathrm{~min}$. The mechanical stir and ultrasonic vibration were employed together.

Finally more nano- $\mathrm{Al}_{2} \mathrm{O}_{3}$ was slowly added to the plating solution in the amount of $10 \mathrm{~g} / \mathrm{l}$ and the content of nano- $\mathrm{Al}_{2} \mathrm{O}_{3}$ in the plating solution was increased to $20 \mathrm{~g} / \mathrm{l}$, then the plating was carried out for $50 \mathrm{~min}$.

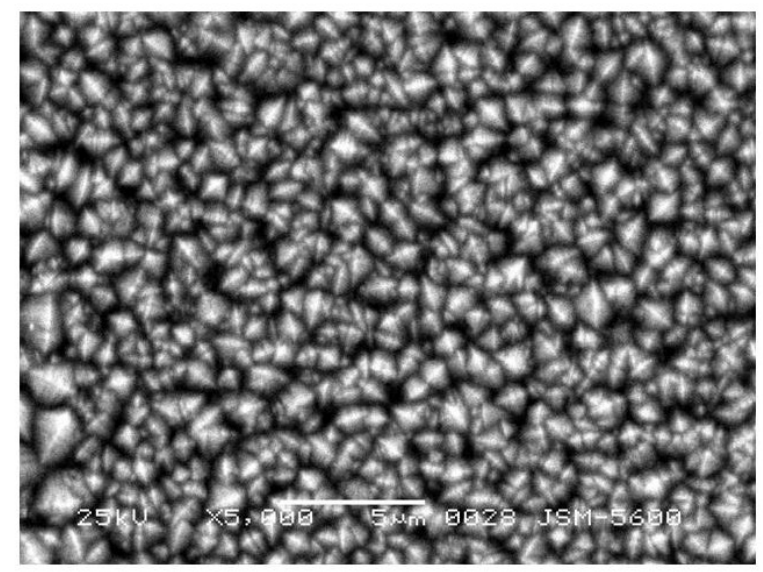

Figure 3: Morphology of $\mathrm{Ni}-\mathrm{Co}$ coating surface without $\mathrm{n}-\mathrm{Al}_{2} \mathrm{O}_{3}$.

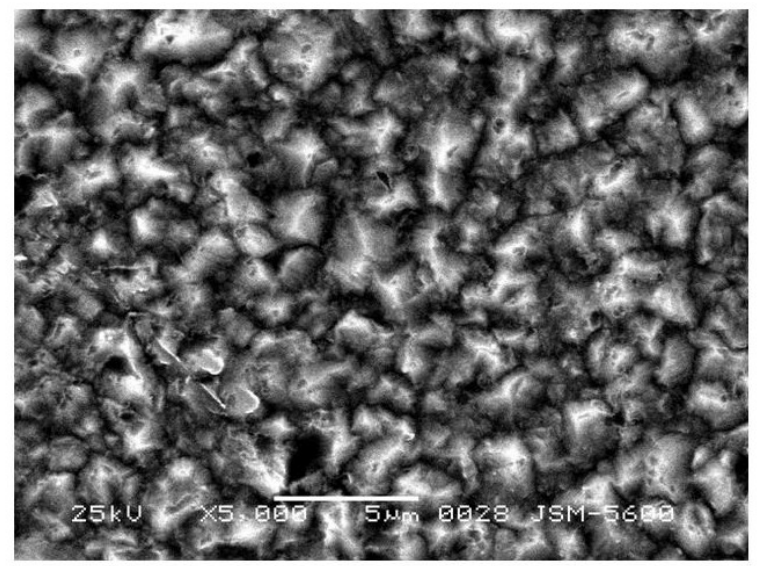

Figure 4: $\quad$ Morphology of $\mathrm{n}-\mathrm{Al}_{2} \mathrm{O}_{3} / \mathrm{Ni}-\mathrm{Co}$ nanocomposite coating surface. 


\section{The microstructure and composition of binmimetic gradient $\mathrm{n}-\mathrm{Al}_{2} \mathrm{O}_{3} / \mathrm{Ni}$-Co nanocomposite coating}

\subsection{Morphology of $\mathrm{Ni}-\mathrm{Co}$ coating and $\mathrm{n}-\mathrm{Al}_{2} \mathrm{O}_{3} / \mathrm{Ni}-\mathrm{Co}$ composite coating}

The morphology of the biomimetic nanocomposite coating surface was observed by means of SEM (JSM-5500LV Japen electronic) (as shown in Fig. 3 and Fig. 4). Compared with a $\mathrm{Ni}$-Co coating, the sizes of crystal grains in the $n-\mathrm{Al}_{2} \mathrm{O}_{3} / \mathrm{Ni}$ Co nanocomposite coating largely decrease due to the dimension effect of nanoparticles. The highly active surface of nanoparticles provides an amount of nucleus for $\mathrm{Ni}$ atoms in the process of electrodeposition. The overpotential of the metal forming nucleus reaction decreases. A composite coating with a fine and dense microstructure was obtained because of the higher nucleation rate [5].

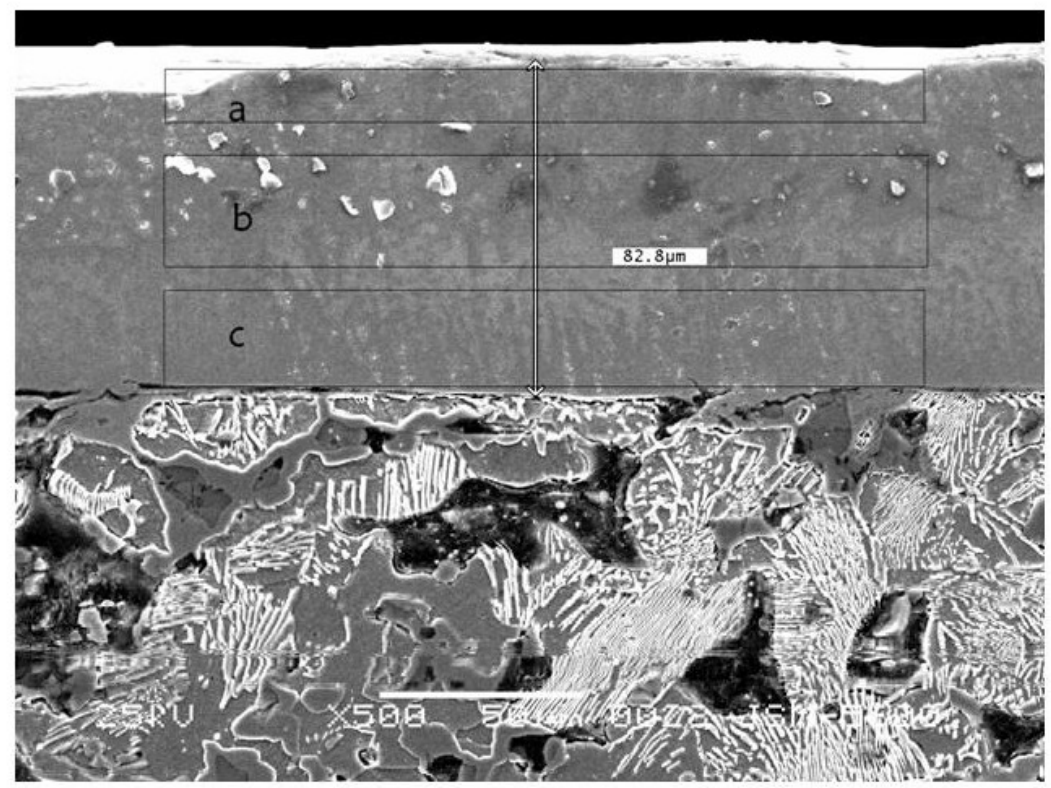

Figure 5: Cross section of the biomimetic gradient $n-\mathrm{Al}_{2} \mathrm{O}_{3} / \mathrm{Ni}-\mathrm{Co}$ nanocomposite coating on the surface of metal metallurgy parts.

\subsection{Analysis of the composition for biomimetic gradient $\mathrm{n}-\mathrm{Al}_{2} \mathrm{O}_{3} / \mathrm{Ni}-\mathrm{Co}$ nanocomposite coating}

The cross section of a biomimetic gradient nanocomposite coating on the surface of metal parts was polished and then was eroded with a $4 \% \mathrm{HNO}_{3}$ alcohol solution. The microstructure of coating section was observed by means of SEM, and the content of the elements was measured by means of energy spectrum. The results show that the thickness of the coating is $82.8 \mu \mathrm{m}$, and the content of 
elements at the different positions on the section changes in gradient (as shown in Fig. 5). Table 1 showed the element contents of different positions in coating. $\mathrm{Al}(\mathrm{wt} \%)$ was the most abundant element in the nano- $\mathrm{Al}_{2} \mathrm{O}_{3}$ in the coating. The result indicated that the content of $\mathrm{Al}$ element is the highest in the upper layer (a) of coating, the content of Al element in the middle layer (b) is less than the upper layer, and the bottom of coating only contains Ni-Co without Al. Therefore, the nano- $\mathrm{Al}_{2} \mathrm{O}_{3}$ content changes in gradient.

Table 1: Distribution of elements in the composite coating.

\begin{tabular}{|l|c|c|c|}
\hline Element content & $\mathrm{Al}(\mathrm{wt} \%)$ & $\mathrm{Co}(\mathrm{wt} \%)$ & $\mathrm{Ni}(\mathrm{wt} \%)$ \\
\hline A (upper layer) & $1.35 \%$ & $9.88 \%$ & $88.77 \%$ \\
\hline B (middle layer) & $0.8 \%$ & $11.88 \%$ & $87.32 \%$ \\
\hline C (bottom layer) & 0 & $8.5 \%$ & $91.5 \%$ \\
\hline
\end{tabular}

\section{Properties of biomimetic gradient $\mathrm{n}-\mathrm{Al}_{2} \mathrm{O}_{3} / \mathrm{Ni}-\mathrm{Co}$ nanocomposite coating}

\subsection{Microhardness}

The microhardness of the composite coating was measured with microsclerometer (HXD-1000TM). Fig. 6 shows the distribution of microhardness of the biomimetic nanocomposite coating from the upper layer to the bottom layer. The result indicated that the upper layer, from the coating surface to a depth of $20 \mu \mathrm{m}$, contains the most nanoparticles, is the hardest and its microhardness was $400 \sim 600 \mathrm{Hv}$. The content of nanoparticles decreases in the middle layer, from $20 \mu \mathrm{m}$ to $65 \mu \mathrm{m}$, and its microhardness was $300 \sim 400 \mathrm{Hv}$ and lower than that of the upper layer. It forms a bottom layer (purity Ni-Co layer), from $65 \mu \mathrm{m}$ to $80 \mu \mathrm{m}$, the microhardness was $130 \sim 300 \mathrm{Hv}$. It forms the substrate when the distance is more than $80 \mu \mathrm{m}$ away from the surface. Consequently, the microhardness of the composite coating changes in gradient from the coating surface to the substrate due to of the change in concentration of nano- $\mathrm{Al}_{2} \mathrm{O}_{3}$.

\subsection{Wettability}

The wettability between water and the biomimetic gradient $n-\mathrm{Al}_{2} \mathrm{O}_{3} / \mathrm{Ni}-\mathrm{Co}$ nanocomposite coating on metal parts surface was determined by measuring the static contact angle of a water droplet (2-3mm diameter) on the nanocomposite coating surface using JC2000A Interface Tension/Contact Angle Measure Equipments (Powereach, China). The experiment was made at $20^{\circ} \mathrm{C}$. The result shows that the wetting angle is up to $97^{\circ}$ (as shown in Fig 7), whereas the metal 
parts are usually hydrophilic after removing oil and other impurities from the surface. So the nanocomposite coating developed has improved water repellence.

There are two main reasons why the coating is hydrophobic. The one is that the surface morphology of the composite coating, which looks like particles or a cauliflower, is different from that of metal parts and belongs to the geometrical non-smooth surface; the another reason is that nano- $\mathrm{Al}_{2} \mathrm{O}_{3}$ grains in the coating are hydrophobic.

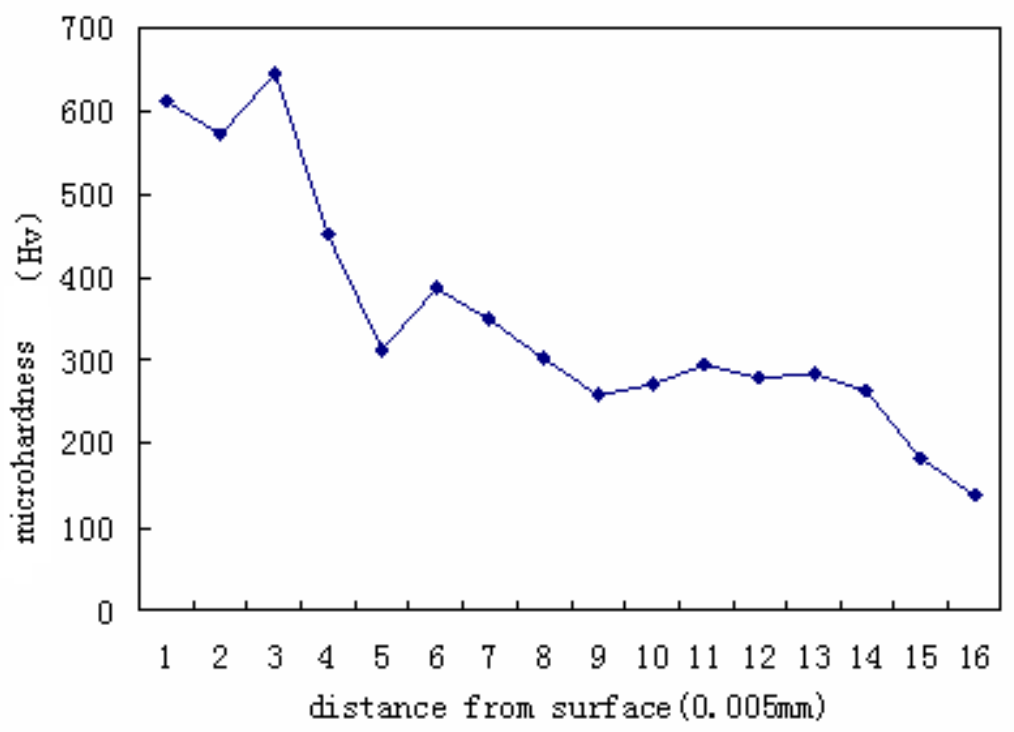

Figure 6: Distribution of microhardnesss in the biomimetic gradient nanocomposite coating.

\section{Conclusions}

(1) According to the characteristic gradient distribution of strengthening fibers in bamboo, biomimetic nano- $\mathrm{Al}_{2} \mathrm{O}_{3}$ composite coatings were designed and prepared on gray cast surface using a nanocomposite electrodeposition method. The optimal technology parameters were obtained from experiments.

(2) The microstructure in the biomimetic nanocomposite gradient coating is dense, the grains are fine, and the contents of nano- $\mathrm{Al}_{2} \mathrm{O}_{3}$ are distributed in gradient.

(3) The microhardness of the nanocomposite coating changes in gradient. Moreover, the wetting angle between water and the composite coating increases obviously and reaches to $97^{\circ}$ at room temperature. 


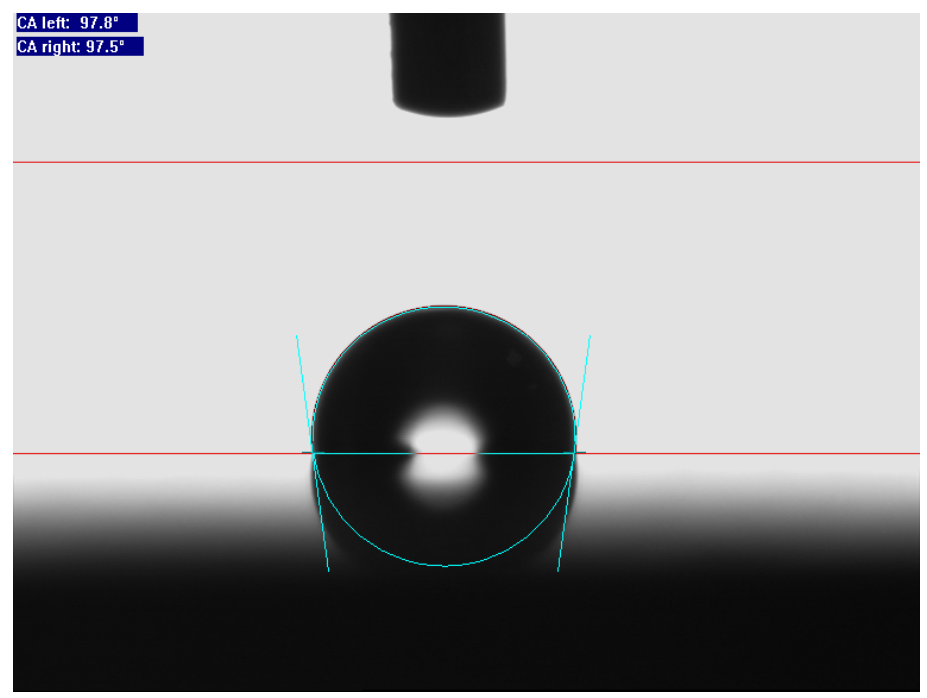

Figure 7: The wetting angle between water and the biomimetic gradient nanocomposite coating.

\section{Acknowledgements}

The authors are grateful for the financial support provided by Trans-Century Training Program Foundation for the Talents by Chinese Ministry of Education (2003) and the Foundation for Distinguished Young Scholars of Jilin Province (Grant No. 20040104)

\section{References}

[1] Hiyoshi Yui. Structure and properties of macromolecule composite materials. Plastic age.1999, 45(4)152 158.

[2] Zhou B L. Some progress in the biomimetic study of composites materials. Mater. Chem. Phys., 1996, 45:114 119.

[3] Zhang Lide, Mo Jimei. Nanomaterials. Shenyang: Liaoning Science and Technology Press, China, 1994.

[4] Lei Shi, Chufeng Sun, Ping Gao. Mechanical properties and wear and corrosion resistance of electrodeposited $\mathrm{Ni}$-Co nanocomposite coating. Applied Surface Science, 2005, (in press)

[5] Lingzhong $\mathrm{Du}, \mathrm{Binshi} \mathrm{Xu}$, Shiyun Dong. Study of tribological characteristics and wear mechanism of nano-particle strengthened nickelbased composite coatings under abrasive contaminant lubrication. Wear, 2004, 257: 1058-1063. 